\title{
Pemanfaatan Limbah Warung Kuliner Menjadi Pupuk Organik di Pantai Depok Kabupaten Bantul
}

\author{
Susanawati*1, Zuhud Rozaki², Mulyono ${ }^{3}$ \\ 1,2Program Studi Agribisnis, Universitas Muhammadiyah Yogyakarta \\ ${ }^{3}$ Program Studi Agroteknologi, Universitas Muhammadiyah Yogyakarta \\ *e-mail: susanawati@umy.ac.id ${ }^{1}$, zaki@umy.ac.id²,mulyono@umy.ac.id ${ }^{3}$
}

\begin{abstract}
Depok Beach is one of the famous beaches in Bantul Regency. Apart from its natural beauty, many culinary stalls sell seafood products on the beach. The large number of visitors at the shop causes a lot of food waste, which causes environmental pollution in the form of smelly and dirty. The practical solution is training and demonstration of a simple composter to convert food waste into organic fertilizer. The implementation method used is counseling, training, and demonstrations of making organic fertilizers. The results that have been achieved include increased knowledge of partners about waste and organic fertilizers and process culinary shop waste into organic fertilizer, either solid or liquid. Laboratory test results on solid organic fertilizers had very high nitrogen content reaching 12.74 percent. The hope is that the utilization of this stall waste can overcome environmental problems and also improve the partner's economy.
\end{abstract}

Keywords: waste, food stall, organic fertilizer, seafood, depok beach

\begin{abstract}
Abstrak
Pantai Depok menjadi salah satu pantai yang populer di Kabupaten Bantul. Selain keindahan alamnya, di pantai tersebut juga banyak ditemukan warung-warung kuliner yang menjual makanan hasil olahan ikan laut. Banyaknya pengunjung di warung tersebut menyebabkan banyak limbah sisa makanan yang membuat pencemaran lingkungan berupa bau dan kotor. Solusi aplikatif adalah pelatihan dan demonstrasi tentang komposter sederhana merubah limbah makanan menjadi pupuk organik. Metode pelaksanaan yang dilakukan adalah penyuluhan, pelatihan dan demonstrasi pembuatan pupuk organik. Hasil yang sudah dicapai antara lain pengetahuan mitra tentang limbah dan pupuk organik meningkat, dan mampu mengolah limbah warung kuliner menjadi pupuk organik, baik padat atau cair. Hasil uji laboratorium pada pupuk organik padat memiliki kandungan Nitrogen sangat tinggi mencapai 12,74 persen. Harapannya dengan pemanfaatan limbah warung ini mampu mengatasi masalah lingkungan dan juga bisa meningkatkan ekonomi mitra.
\end{abstract}

Kata kunci: limbah, warung kuliner, pupuk organi, seafood, pantai depok

\section{PENDAHULUAN}

Perkembangan wisata di Daerah Istimewa Yogyakarta (DIY) menjadi perhatian banyak pihak (DIY, 2019). Salah satu daerah yang berkembang adalah Kabupaten Bantul, dimana terdapat 12 pantai di yang menjadi daya tarik wisata DIY, salah satu pantai yang terkenal dan banyak didatangi masyarakat adalah Pantai Depok (Nawawi, 2015). Selain pasir hitam yang menjadi daya tari, banyak warung kuliner yang berdiri di tepi kawasan Pantai Depok dengan menjual hasil olahan laut untuk pengunjung (Kurniaty et al., 2017; Yulianto, 2018), seperti terlihat pada Gambar 1.

Pengunjung warung kuliner di Pantai Depok pada hari biasa rata-rata 5-7 kloter, dimana masing-masing kloter terdiri dari 2-3 orang. Jumlah tersebut berbeda dengan saat akhir pekan atau libur nasional yang bisa mencapai 30-40 kloter setiap harinya. Banyaknya pengunjung di warung kuliner Pantai Depok membuat banyak limbah sisa makanan yang terkumpul, seperti terlihat pada Gambar 2. Limbah sisa makanan dari pengunjung dalam satu hari dapat terkumpul dua sampai tiga ember besar untuk satu warung. Selama ini, banyak limbah sisa makanan tersebut hanya dibuang tanpa diolah sama sekali, sehingga menyebabkan pencemaran lingkungan berupa bau dan kotor. 


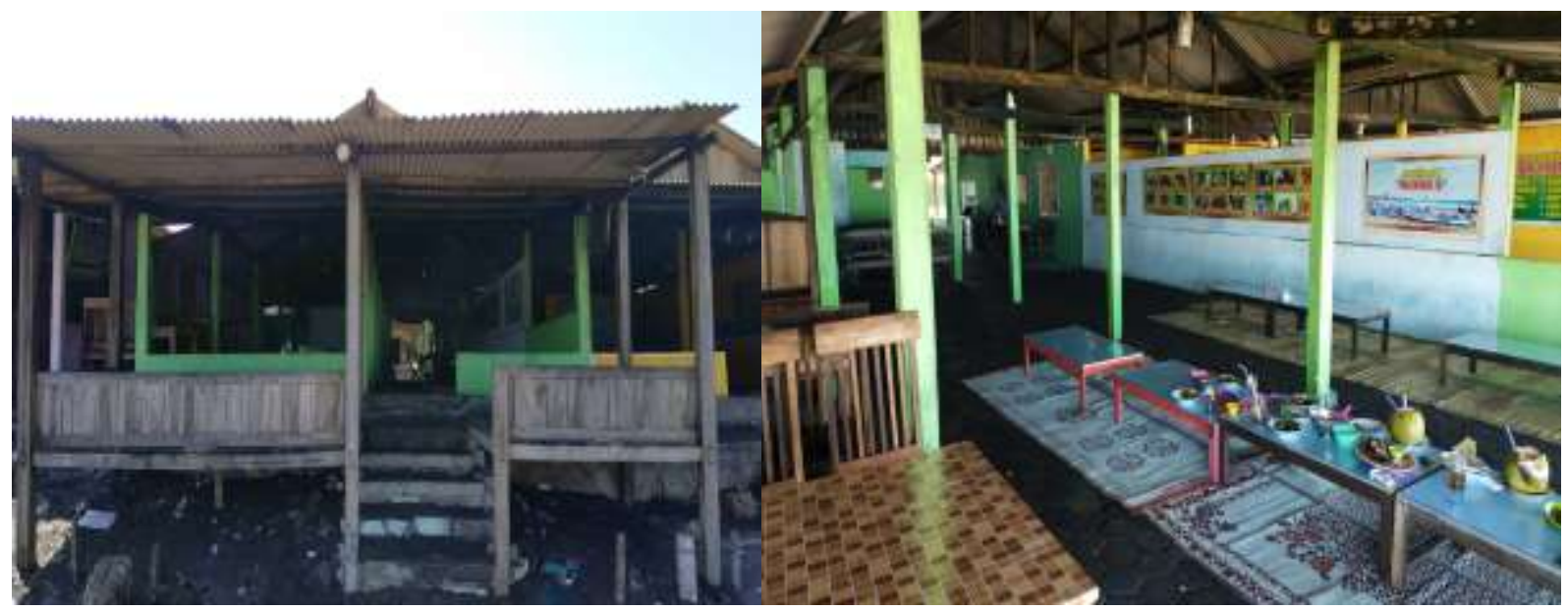

Gambar 1. Warung Kuliner di Pantai Depok

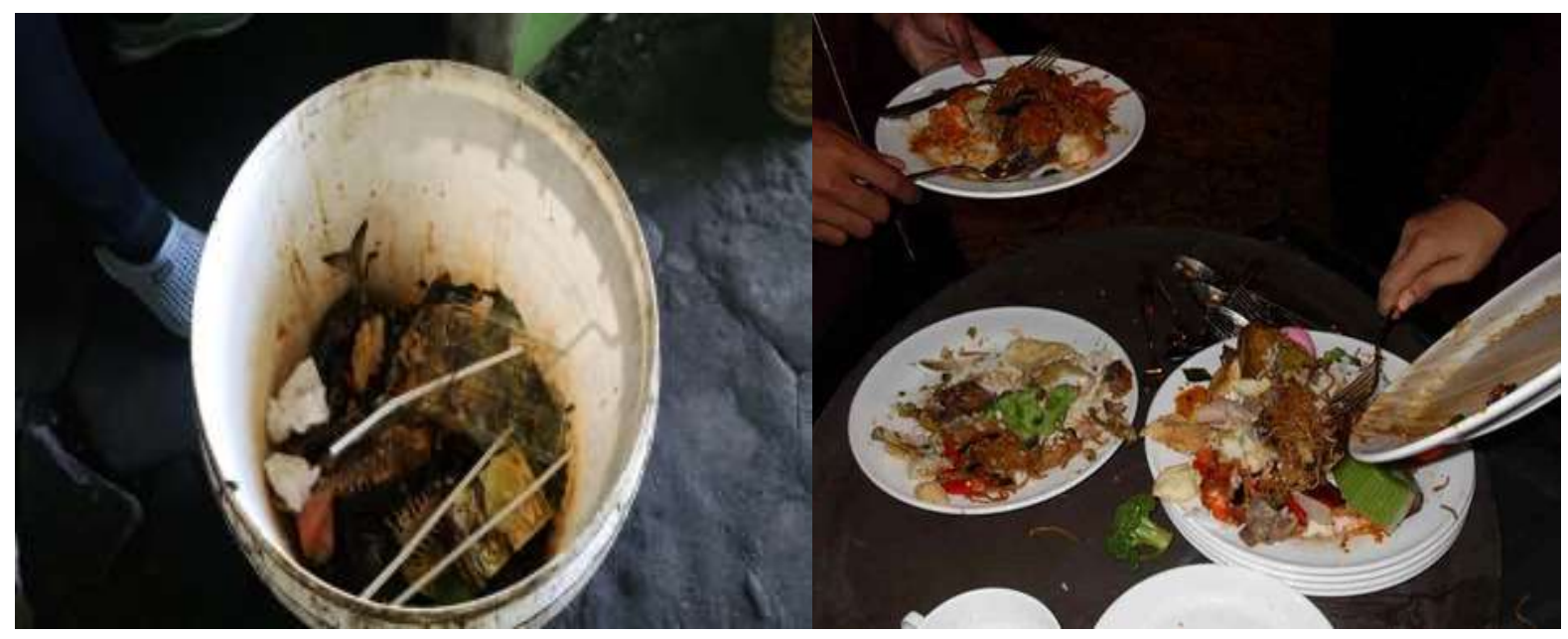

Gambar 2. Limbah Sisa Makanan dan Tulang Ikan di Warung Kuliner Pantai Depok

Permasalahan limbah makanan, termasuk dari warung kuliner, sudah menjadi problem bagi banyak wilayah, baik perkotaan ataupun pedesaan. Tanpa solusi yang baik, pencemaran lingkungan bisa bertambah buruk dan akan berdampak pada kehidupan sekitar (Dewilda et al., 2019; Wulansari et al., 2019). Pengolahan limbah makanan dengan daur ulang atau cara lain seperti mengolahnya menjadi pupuk organik merupakan langkah solutif yang bisa dilakukan (Sari et al., 2018). Alternative solusi ini bisa membantu menanggulangi masalah limbah sisa makanan dan juga mampu meningkatkan pendapatan warung kuliner yang tergabung di Pantai Depok dan kesehatan lingkungan sekitar warung. Oleh karena itu, kegiatan pengabdian ini bertujuan meningkatkan kesadaran pengelola warung kuliner akan pentingnya mengelola sampah, dan memanfaatkannya menjadi sesuatu yang bernilai ekonomi (pupuk organik). Lin et al. (2019) menyampaikan bahwa pupuk organik mampu membantu upaya pertanian berkelanjutan. Kandungan pupuk organik sanga bagus untuk tanaman (Rozaki et al., 2020). Bande et al. (2020) menyampaikan juga bahwa pengadaaan pupuk organik mampu membantu petani untuk mengurangi atau menghilangkan ketergantungan terhadap pupuk kimia. Serta, menurut David \& Ardiansyah (2017), potensi pasar pupuk organik terus meningkat seiring dengan kesadaran akan bahaya pupuk kimia yang terus meningkat.

\section{METODE}

Kegiatan pengabdian ini memiliki sasaran yaitu pemilik warung kuliner di Pantai Depok, Kabupaten Bantul yang tergabung pada Paguyuban Mina Bahari 45. Dengan target utama untuk 
memanfaatkan limbah warung kuliner mnejadi pupuk organik baik padat ataupun cair. Ada beberapa metode yang dipakai untuk mencapai kegiatan pengabdian ini, yaitu:

Penyuluhan dan Focus Group Discussion (FGD)

Kegiatan ini dilakukan dengan mengumpulkan mitra sasaran strategis yaitu Paguyuban Warung Kuliner Mina Bahari 45 untuk berpartisipasi dalam ceramah, penyuluhan dan diskusi tentang pengelolaan teknik pembuatan pupuk organik secara umum dan dari limbah warung kuliner.

\section{Pelatihan dan Demonstrasi}

Kegiatan ini terbagi dalam beberapa tahapan, yaitu :

a. Transfer Teknologi Tepat Guna (TTG)

Transfer TTG dilakukan lewat teknologi pembuatan pupuk organik dan pemberian komposter sederhana kepada Paguyuban Warung Kuliner Mina Bahari 45. Tujuannya agar usaha warung kuliner ini bisa mengurangi limbah sisa warung kuliner dari pengunjung dan mampu meningkatkan pendapatan mitra.

b. Demonstrasi dan praktek

Kegiatan ini dilakukan dengan mendemontrasikan cara memilah limbah sisa makanan. Limbah sisa makanan dimasukkan dalam komposter sederhana dan diproses menjadi pupuk organik. Kemudian dijelaskan dengan detail kerangka komposter sehingga mampu memproses sisa makanan menjadi pupuk organik. Juga disampaikan bagaimana membuat alat komposter ini, sehingga masyarakat lainnya bisa mengadopsi alat ini di masa mendatang.

c. Pendampingan dan Konsultasi

Kegiatan pengabdian ini dilakukan dengan cara berkesinambungan, dengan tujuan membina dan mendampingi mitra strategis sampai berhasil memanfaatkan TTG secara bijak dan tepat dalam menghasilkan pupuk organik.

Pengujian Pupuk Organik

Kegiatan ini dilakukan di Lab. Tanah, Fakultas Pertanian, Universitas Muhammadiyah Yogyakarta, untuk mengetahui kandungan unsur hara yang dimiliki pupuk dari limbah warung kuliner di Pantai Depok. Dengan diketahuinya kandungan unsur hara tersebut, akan mampu menentukan dosis penggunaan dari pupuk organik yang bisa dicantumkan dalam kemasan nantinya. Selain itu, ketika dipasarkan mampu menjadi nilai tambah tersendiri karena terdapat informasi kandungan unsur hara dari pupuk yang dituliskan dalam label kemasan.

Monitoring dan Evaluasi

Kegiatan ini dilakukan baik sebelum, ketika dan sesudah pelaksanaan setiap agenda pengabdian dengan melibatkan semua pihak terkait. Hal ini dilakukan untuk menjadi bahan perbaikan pada kesempatan yang lainnya.

\section{HASIL DAN PEMBAHASAN}

Kondisi Umum

Warung kuliner di Pantai Depok tergabung dalam Paguyuban "Mina Bahari 45". Paguyuban tersebut berdiri sejak tahun 1998, didipimpin oleh Bapak Tarmanto dan sampai saat ini memiliki anggota sebanyak 50 sampai 60 warung kuliner. Sebagian besar warung kuliner di Pantai Depok merupakan warung lesehan dengan menempati bangunan permanen hasil swadaya mereka sendiri. Kegiatan di paguyuban Mina Bahari 45 antara lain arisan, jeladri (sedekah laut) dan menyambut serta melayani pengunjung yang datang di pantai Depok. Pengunjung warung kuliner di Pantai Depok pada hari biasa rata-rata hanya 5-7 kloter, dimana masing-masing kloter 
terdiri dari 2-3 orang. Jumlah tersebut berbeda dengan saat weekend atau libur nasional yang bisa sampai 30-40 kloter di setiap harinya.

\section{Peningkatan Pengetahuan tentang Limbah dan Potensi untuk Pupuk Organik}

Masyarakan sasaran, yaitu pemilik warung kuliner, secara umum belum memahami permasalah sampah yang diakibatkan oleh warung kuliner mereka. Biasanya limbah makanan dari warung hanya dibuang begitu saja dengan mempekerjakan tukang sampah. Pengetahuan tentang pentingnya pengelolaan sampah, atau pemanfaatan sampah perlu ditingkatkan. Dalam kegiatan pengabdian ini, dilakukan penyuluhan untuk meningkatkan pengetahuan tentang pengelolaan sampah dan potensi pemanfaatan limbah warung kuliner menjadi pupuk organik (Gambar 3). Nara sumber yang didatangkan adalah pakar tentang lingkungan dan pupuk organik, dengan materi yang disampaikan bisa dilihat pada tabel 1. Peserta sangat antusias dalam mengikuti kegiatan penyuluhan tersebut, karena sebelumnya belum pernah ada kegiatan serupa. Sebelum dan setelah penyuluhan peserta diminta mengerjakan pre-test dan post-test untuk melihat kemampuan peserta tentang limbah dan pupuk organik. Hasil dari pre-test dan post-test menunjukkan bahwa pengetahun sasaran akan limbah dan potensi pupuk organik dari limbah warung kuliner meningkat.

Tabel 1. Materi Penyuluhan dan FGD di Paguyupan Warung Kuliner Mina Bahari

\begin{tabular}{|c|c|c|}
\hline No & Materi & Sub-Materi \\
\hline 1. & $\begin{array}{l}\text { Pemanfaatan limbah } \\
\text { warung kuliner }\end{array}$ & $\begin{array}{l}\text { - Jenis-jenis limbah dari warung kuliner olahan } \\
\text { hasil laut } \\
\text { - Potensi pemanfaatan limbah warung kuliner }\end{array}$ \\
\hline 2. & $\begin{array}{l}\text { Pupuk kompos atau pupuk } \\
\text { organik yang berkualitas }\end{array}$ & $\begin{array}{l}\text { - Berbagai jenis pupuk } \\
\text { - Syarat pupuk kompos atau pupuk organik } \\
\text { yang berkualitas }\end{array}$ \\
\hline
\end{tabular}

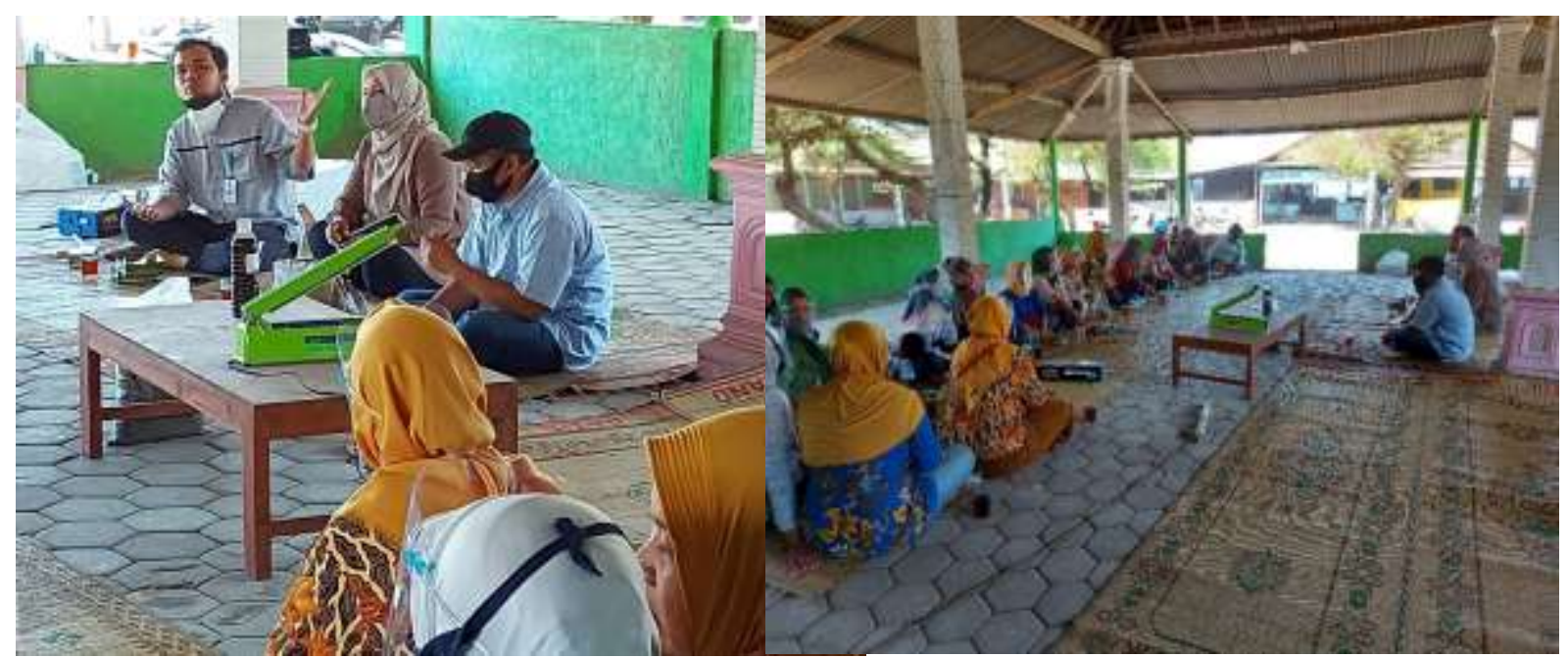

Gambar 3. Penyuluhan Tentang Pupuk Organik

Pelatihan Pembuatan Pupuk Organi Menggunakan Komposter

Kegiatan pengabdian tidak berhenti pada upaya peningkatan pengetahuan tentang pengolahan sampah dan pembuatan pupuk organik dari limbah warung kuliner. Kegiatan selanjutnya ada pelatihan pembuatan pupuk organik, disertai dengan fasilitasi komposter sederhana sebanyak 30 buah yang dilakukan secara bertahap (Gambar 4). Pelatihan pembuatan 
pupuk organik dilakukan untuk membantu sasaran bisa membuat pupuk organik secara mandiri dan berkelanjutan (Sari et al., 2018). Kegiatan pelatihan diawali dengan memberitahukan cara memilah limbah sisa makanan, limbah berupa nasi, sisa ikan, sayuran dan lainnya dimasukkan dalam komposter sederhana dan diproses menjadi pupuk organik (Gambar 5). Kemudian dijelaskan juga detail kerangka komposter sehingga mampu memproses sisa makanan menjadi pupuk organik. Selain itu juga disampaikan cara membuat alat komposter, sehingga masyarakat lainnya bisa mengadopsi alat ini di masa mendatang. Pemilik warung kuliner yang hadir sangat antusias dan semangat berpartisipasi pada kegiatan demo ini, hal ini ditunjukkan dengan tingkat kehadiran dan persiapan pengadaan limbah warung kuliner untuk demo tersebut. Masyarakat sasaran dilatih agar rajin memilah limbah agar hasil pupuk organik bisa optimal. Pada kesempatan ini juga dibentuk pengurus organisasi pengolahan limbah warung kuliner menjadi pupuk organik, agar kegiatan pengabdian ini bisa terus berjalan dengan baik. Perlu ada organisasi pengelola agar managemen produksi dan pemasaran bisa lebih baik dalam sebuah proses pembuatan pupuk organik (Elpawati et al., 2013). Dalam perjalannya juga dilakuakn monitoring seperrti tampak pada Gambar 6.

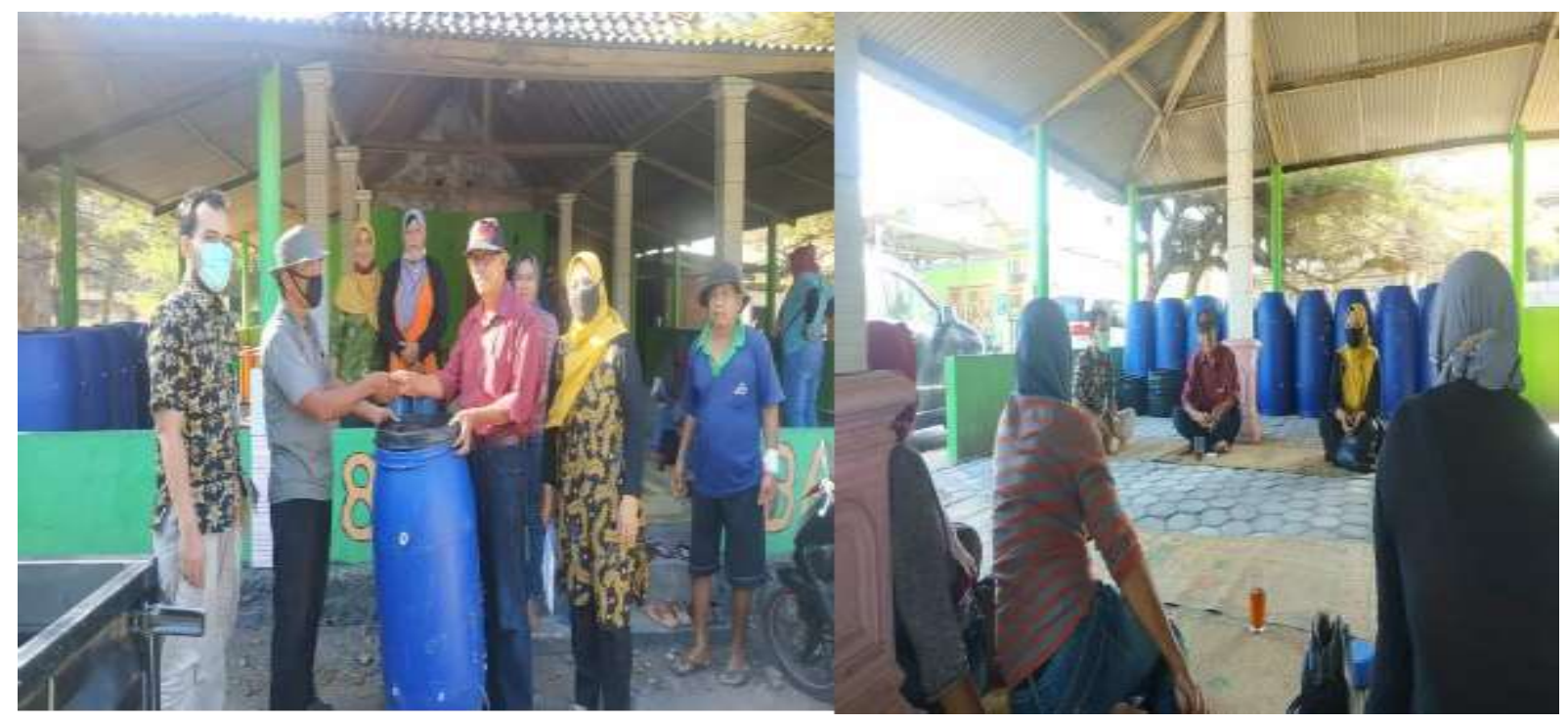

Gambar 4. Penyerahan Komposter kepada Mitra

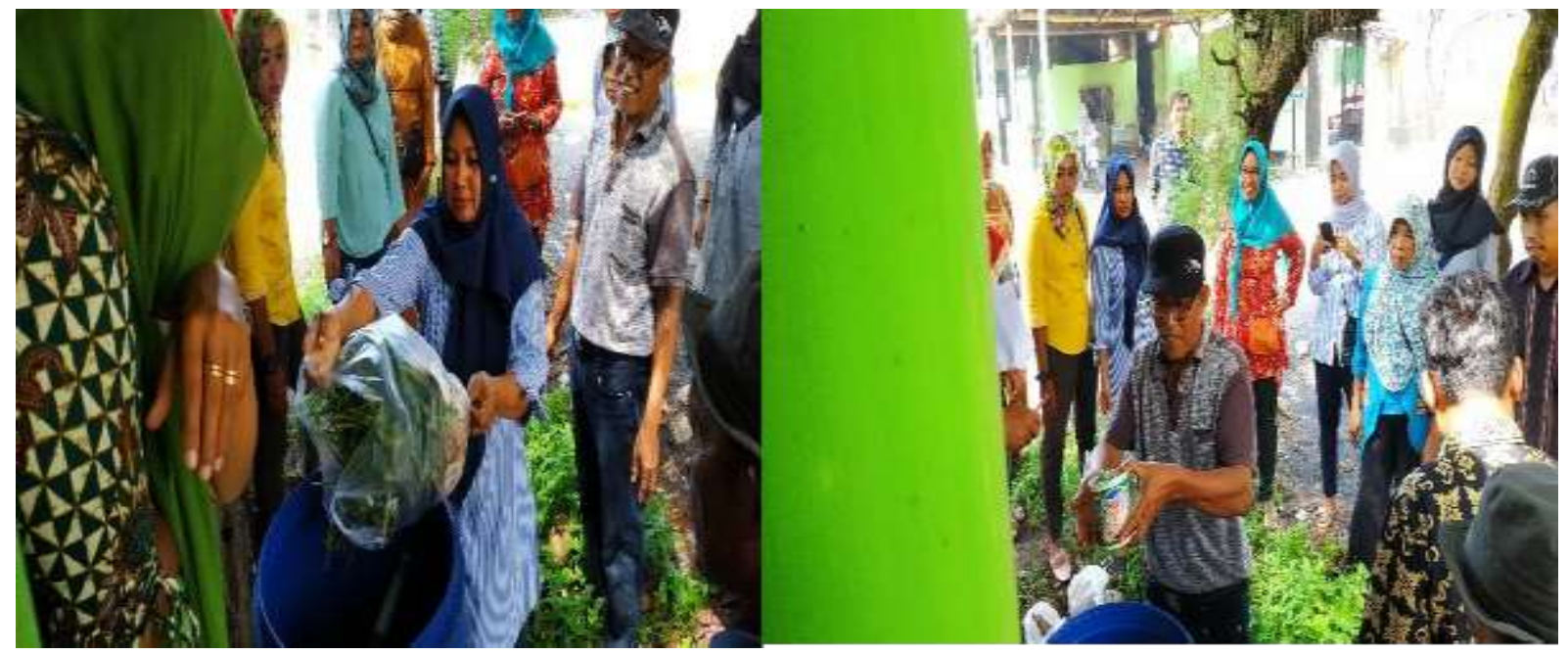

Gambar 5. Pelatihan Pembuatan Pupuk Organik dari Limbah Warung Kuliner 


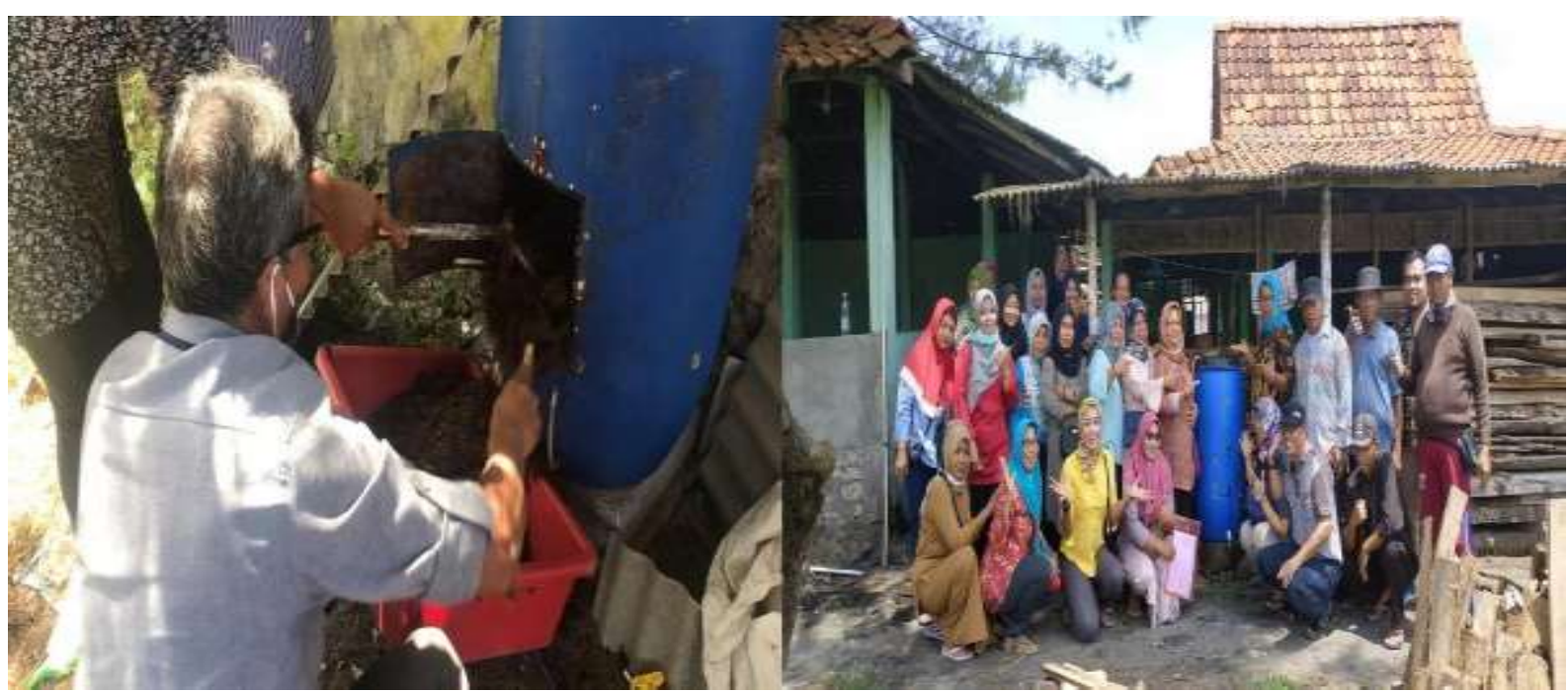

Gambar 6. Monitoring Mitra

Uji Laboratorium Pupuk Organik Hasil Mitra

Sekitar dua bulan sampai tiga bulan setelah pelatihan, tim pengabdian kembali untuk mengambil pupuk organik yang dihasilkan. Didapat pupuk organik padat dan cair, keduanya kemudian diuji di Labroratorium Tanah, Fakultas Pertanian, Universitas Muhammadiyah Yogyakarta. Uji tersebut dilakukan untuk mengetahui kandungan unsur hara makro dari pupuk tersebut. Hasil uji kandungan hara makro pupuk organik tersebut bisa dilihat di tabel 3.

Tabel 1. Hasil Uji Laboratorium

\begin{tabular}{lrr}
\hline \multicolumn{1}{c}{ Unsur hara } & Pupuk Organik Padat & Pupuk Organik Cair (POC) \\
\hline Kadar Carbon (\%) & 21.35 & 5.35 \\
Bahan organik (\%) & 36.58 & 9.72 \\
Nitrogen total (\%) & 12.74 & 5.22 \\
C/N ratio & 1.67 & 1.02 \\
Phospor total (ppm) & 568.93 & 23.11 \\
Kalium total (ppm) & 1482.16 & 1981.21 \\
\hline
\end{tabular}

\section{KESIMPULAN}

Rangkain kegiatan pengabdian yang sudah dilakukan diharapkan mampu meningkatkan pengetahuan masyarakat sasasaran tentang pengolahan sampah dan pemanfaatan limbah warung kuliner menjadi pupuk organi. Dari berbagai pembahasan yang diatas, dapat ditarik beberapa kesimpulan sebagai berikut:

1. Limbah warung kuliner di Pantai Depok, Kabupaten Bantul memiliki potensi untuk diproses menjadi pupuk organik baik padat atau organik.

2. Sasaran pengabdian ini menunjukkan antusiasme yang tinggi terkait upaya peningkatan pengetahuan mereka tentang pengelolaan sampah dan pemanfaatan limbah warung kuliner menjadi pupuk organik. Pengetahuan mereka menjadi meningkat lewat pre-test dan post-test yang dilakukan.

3. Pelatihan dan demonstrasi pembuatan pupuk organik dilakukan dengan menghibahkan komposter sederhana membuat minat sasaran menjadi lebih tinggi. Sasaran lebih mudah untuk mempraktekkan sendiri pembuatan pupuk organik baik padat atau cair. 
4. Hasil pengujian laboratorium terhadap hasil pupuk organik menunjukkan kandungan $\mathrm{N}$ yang cukup tinggi, hal ini menunjukkan produk hasil pengabdian ini memiliki keunggulan jika dipasarkan. Sasaran perlu lebih fokus dalam pemilahan limbah warung kuliner saat dimasukkan dalam komposter agar hasil pupuk organiknya lebih baik lagi.

\section{UCAPAN TERIMA KASIH}

Penulis mengucapkan terima kasih kepada Kementrian Riset dan Teknologi / Badan Riset dan Inovasi Nasional Deputi Bidang Penguatan Riset dan Pengembangan yang telah memberikan dana hibah Skema PKM Tahun Anggaran 2020, sehingga kegiatan pengabdian masyarakat ini dapat berjalan dengan lancar. Terima kasih juga kepada Universitas Muhammadiyah Yogyakarta melalui LP3M yang telah memberikan dukungan dalam kegiatan ini.

\section{DAFTAR PUSTAKA}

Bande, L. O. S., Khaeruni, A., Saefuddin, Haetami, A., Alwi, L., Mariadi, \& Satrah, V. N. (2020). Pelatihan Pembuatan Pupuk Hayati, Agens Hayati dan Pestisida Nabati Desa Aunupe Kabupaten Konawe Selatan. DINAMISIA: Jurnal Pengabdian Kepada Masyarakat, 4(1), 193200. https://doi.org/https://doi.org/10.31849/dinamisia.v4i1.358610.31849

David, W., \& Ardiansyah. (2017). Organic agriculture in Indonesia: challenges and opportunities. Organic Agriculture, 7(3), 329-338. https://doi.org/10.1007/s13165-016-0160-8

Dewilda, Y., Aziz, R., \& Fauzi, M. (2019). Kajian Potensi Daur Ulang Sampah Makanan Restoran di Kota Padang. Jurnal Serambi Engineering, 4(2), 482-487. https://doi.org/10.32672/jse.v4i2.1325

DIY, D. P. (2019). Statistik Kepariwisataan DIY 2018. In Dinas Pariwisata DIY. https://visitingjogja.com/19962/statistik-pariwisata-diy-2018/

Elpawati, E., Herlambang, M., \& Mahbubi, A. (2013). Strategi Pengembangan Bisnis Pupuk Rumah Kompos Uin Jakarta. Agribusiness Journal, 7(1), 105-128. https://doi.org/10.15408/aj.v7i1.5173

Kurniaty, R. T., Lustiyati, E. D., \& Nisati, N. (2017). Hubungan Praktik Higiene Sanisitasi Dengen Cemaran Bakteri Escherichia colo Pada Olahan Ikan Bakar di Warung Makan Seafood Pantai Depok, Bantul, Yogyakarta. Jurnal Formil (Forum Ilmiah) KesMas Respati, 2(2), 53-63.

Lin, W., Lin, M., Zhou, H., Wu, H., Li, Z., \& Lin, W. (2019). The effects of chemical and organic fertilizer usage on rhizosphere soil in tea orchards. PLoS ONE, 14(5), 1-16. https://doi.org/10.1371/journal.pone.0217018

Nawawi, A. (2015). Partisipasi Masyarakat Dalam Pengelolaan Wisata Pantai Depok Di Desa Kretek Parangtritis. Partisipasi Masyarakat Dalam Pengelolaan Wisata Pantai Depok Di Desa Kretek Parangtritis, 5(2), 103-109. https://doi.org/10.22146/jnp.6370

Rozaki, Z., Salassa, D. I., \& Nugroho, R. B. (2020). Farmers' responses to organic rice farming in Indonesia: Findings from central Java and south Sulawesi. Open Agriculture, 5(1), 703-710. https://doi.org/10.1515/opag-2020-0070

Sari, M., Lestari, S. U., \& Awal, R. (2018). Peningkatan Ketrampilan Mahasiswa Dalam Pengelolaan Sampah Organik Untuk Mewujudkan Green Campus Di Universitas Lancang Kuning. Dinamisia: Jurnal Pengabdian Kepada Masyarakat, 2(2), 193-196. https://doi.org/10.31849/dinamisia.v2i2.1392

Wulansari, D., Ekayani, M., \& Karlinasari, L. (2019). Kajian Timbulan Sampah Makanan Warung Makan. ECOTROPHIC : Jurnal Ilmu Lingkungan (Journal of Environmental Science), 13(2), 125. https://doi.org/10.24843/ejes.2019.v13.i02.p01

Yulianto, A. (2018). Destinasi dan Strategi Pengembangan Daya Tarik Wisata Pantai di Kabupaten Baperingkatntul Yogyakarta. Jurnal Media Wisata, 16(1), 651-661. https://doi.org/10.1017/CB09781107415324.004 